\title{
SIMULATION OF MECHANICAL PARAMETERS OF SPRAYER BOOM
}

\author{
Dragos Manea $^{1}$, Mihai Gidea ${ }^{2}$, Eugen Marin ${ }^{1}$, Marinela Mateescu ${ }^{1}$ \\ ${ }^{1}$ National Institute of Research-Development for Machines and Installations Designed to Agriculture \\ and Food Industry, Romania; ${ }^{2}$ University of Agronomic Sciences and Veterinary \\ Medicine of Bucharest, Romania \\ manea_dragos_05@yahoo.com, gideam@yahoo.com,marin_43eu@yahoo.com, \\ marinelamateescu@yahoo.com
}

\begin{abstract}
The sprayer boom is a large and complex structure, used to support the spray nozzles. It is important to control and minimize the vibration of the structure on the vertical and horizontal planes, in order to insure the uniformity of pulverization over the field. Owing to the large spray boom widths, flexible behaviour of spray booms becomes important. Even small deformations of the structure can cause, by the large spray boom width, considerable displacements at the boom tips. However, there is not a clear correlation between the boom width and the amount of the spray boom motion. Another important factor is whether it concerns a trailed or a mounted sprayer. As spray boom motions play a dominant role on the spray distribution pattern, spray boom stability is important. Theoretical studies, simulations and field experiments have indicated that due to the spray boom vibrations, spray deposit distribution varies between 0 and $80 \%$. In this paper the static and dynamic study of a sprayer boom structure of about $24 \mathrm{~m}$ length is presented. Starting from the CAD model of the sprayer boom structure, a standard mesh procedure as a preprocessing step of a finite element analysis has been followed. Mainly shells, a reduced number of solid elements and rigid connection elements were used. The purpose of the static linear analysis was to determine the state of tension and deformation that develop in the boom during its exploitation. The geometric model made for the linear static analysis using the finite element method comprises several steps and highlights the mechanical response of the structure. An important parameter of the dynamic behaviour is the boom vibration amplitude. This parameter was observed in the finite element analysis of the boom structure considered at a natural scale. Other similar parameters, such as the resonant frequencies, have been observed.
\end{abstract}

Keywords: boom, simulation, finite element analysis.

\section{Introduction}

In the last decades, the width of boom sprayers has increased drastically. Nowadays, sprayers having a width of $45 \mathrm{~m}$ are commercially available. Owing to the large spray boom widths, flexible behaviour of spray booms becomes important. Even small deformations of the structure can cause, by the large spray boom width, considerable displacements at the boom tips [1].

Theoretical studies, simulations and field experiments have indicated that due to the spray boom vibrations, spray deposit distribution varies between 0 and $80 \%[2 ; 3]$. Structure dynamics is a very broad discipline, which uses a huge arsenal of theoretical and experimental methods to solve a fundamental problem of structures: the dynamic response to variable tasks over time [4- 8]. Vibrations and especially vibration in resonance modes are problems that occur frequently in large structures. Because large structures with large numbers of components cannot be optimally engineered for resonant regimes, it is often done to modify the structures or improve them using the modal analysis of these structures [9].

In the paper [10], the dynamic study of a sprayer boom structure of about $12 \mathrm{~m}$ length on each side was presented. Initially, the real boom has been optimized in terms of minimizing the vertical vibration, considering the dynamic model of the whole sprayer mechanism excited from the ground, when it is following a standard bumpy path.

In this paper the static and dynamic study of a sprayer boom structure of about $24 \mathrm{~m}$ length is presented. The purpose of the static and dynamic linear analysis was to determine the state of tension and deformation that develops in the boom during its exploitation. The linear static analysis using the finite element method comprises several steps and highlights the mechanical response of the structure. An important parameter of the dynamic behavior was the boom vibration amplitude. This parameter was observed in the finite element analysis of the boom structure considered at a natural scale. Other similar parameters, such as the resonant frequencies, have been calculated. 


\section{Materials and methods}

The analyzed structure is a boom of a trailed spraying machine (Figure 1), with a working width of $24 \mathrm{~m}$, used to apply phytosanitary treatments and fertilization in field crops. The finite element method was used, working in the SolidWorks 2013 Simulation package [11]. Solid Works Simulation contains real-time design, testing, and simulation tools (the product is subjected to the same conditions it will endure in real life), leading to an accelerated design process, increased design quality and productivity, at the same time lowering the cost of testing prototypes before proceeding with the manufacturing process.

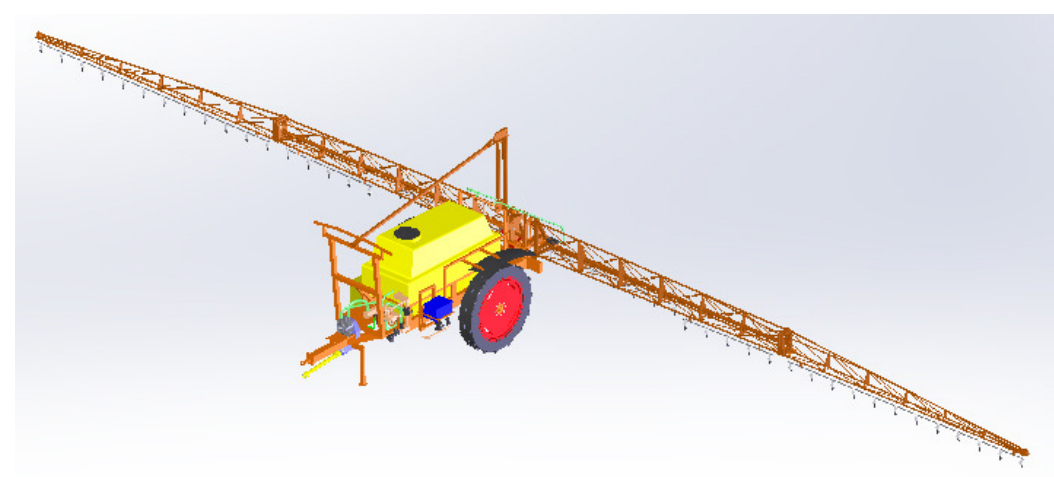

a) working position

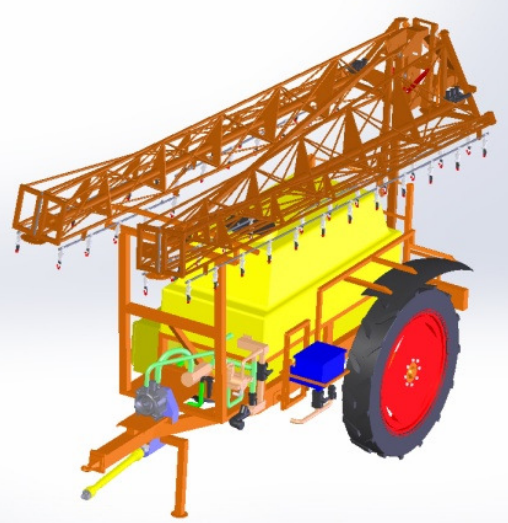

b) folded boom for transport

Fig. 1. Trailed boom sprayer - 3D model

The first step of this study was the static linear analysis. The purpose of static linear analysis was to determine the state of tension and deformation that develops in the boom of the spraying machine during its exploitation. The geometric model made for the linear static analysis using the finite element method comprises several steps, which will be presented below, and highlights the mechanical response of the structure. Due to the symmetry of the geometric model, only half of it was considered for the static analysis (Figure 2). From the point of view of the location of the component elements of the investigated structure, it was considered that they are positioned according to the real case of its operation in the field.

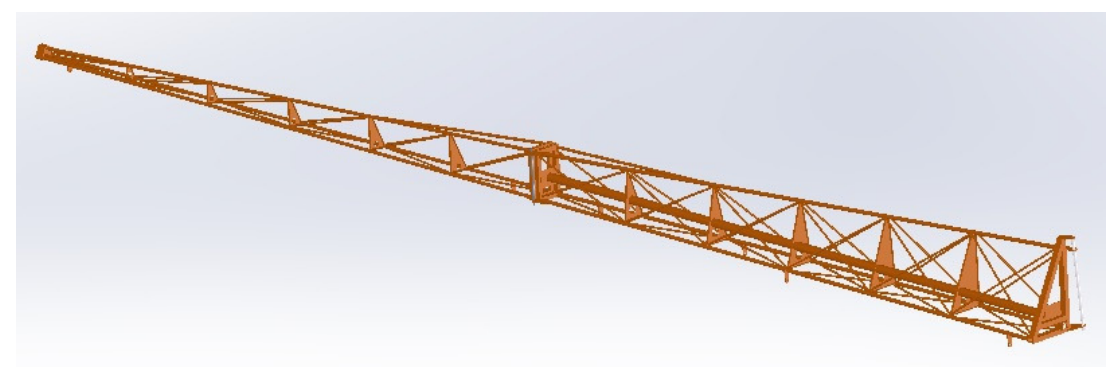

Fig. 2. Geometric model of analyzed structure (half boom, $12 \mathrm{~m}$ width)

The discretization of the boom structure was made by modifying certain parameters so that the finite element network obtained from the meshing process is a continuous network to be adapted to the geometrically developed model without obtaining distorted areas that could have led to incorrect results. The finite element network obtained after the meshing process is shown in Figure 3.

Analyzing Figure 3, it can be seen that the dimensions of the mesh network elements are relatively small. This was desirable in the meshing process to make the model optimal and to make a mathematical model as accurate as possible. Thus, the condition that the smallest dimension of an element be equal to the smaller geometric dimension corresponding to a component of the assembly was imposed. The finite element network resulting from the meshing process consists of 960837 elements and 271442 nodes. The types of finite elements used in the meshing process are threedimensional Solid type elements.

The material of the boom structure is S235JR steel, with hypothetical linear, elastic, homogeneous and isotropic behaviour. The characteristics of the S235JR steel that were used for the analyzed 
structure, taken from the SolidWorks material database are the following: elastic modulus $2.10000003+011 \mathrm{~N} \cdot \mathrm{m}^{-2}$, Poisson's ratio $0.28 ;$ mass density $7800 \mathrm{~kg} \cdot \mathrm{m}^{-3}$, tensile strength $360000 \mathrm{kN} \cdot \mathrm{m}^{-2}$ and yield strength $235000 \mathrm{kN} \cdot \mathrm{m}^{-2}$.
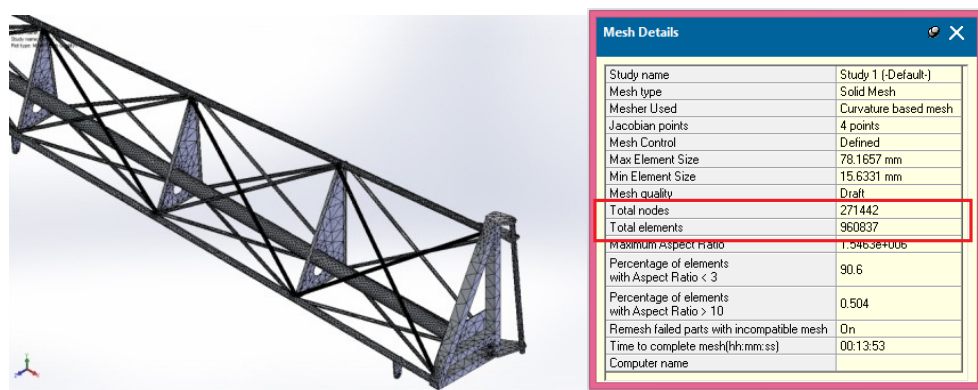

Fig. 3. Meshline appearance and meshing parameters

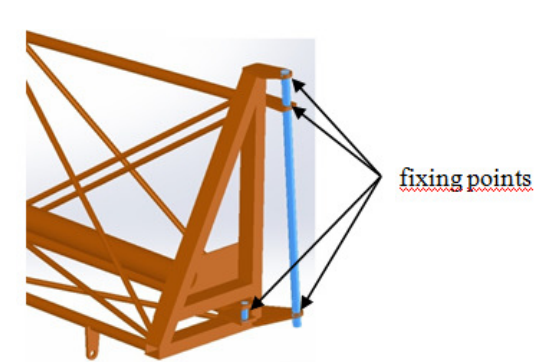

Fig. 4. Boom structure fixing points

The next step was to establish the fixing points and apply the external loads. The boom structure was fixed at its points of attachment to the central folding / unfolding device (Figure 4). The loading of the structure is pure gravitational (its own weight), the gravitational acceleration having the value $9.81 \mathrm{~m} \cdot \mathrm{s}^{-2}$, on the vertical direction.

\section{Results and discussion}

Figure 5 presents the main results of linear static analysis, namely: von Misses equivalent stress, relative static displacement (URES), strain (ESTRN), and factor of safety (FOS) distribution. It is observed that the maximum equivalent stress $\left(2.29 \cdot 10^{8} \mathrm{~N} \cdot \mathrm{m}^{-2}\right)$ is less than the yield strength $\left(2.35 \cdot 10^{8} \mathrm{~N} \cdot \mathrm{m}^{-2}\right)$ of the structure material. Under its own weight, the maximum displacement of the structure is approximately $7 \mathrm{~mm}$, corresponding to the boom end. Factor of safety plot shows min FOS is 1.02 .

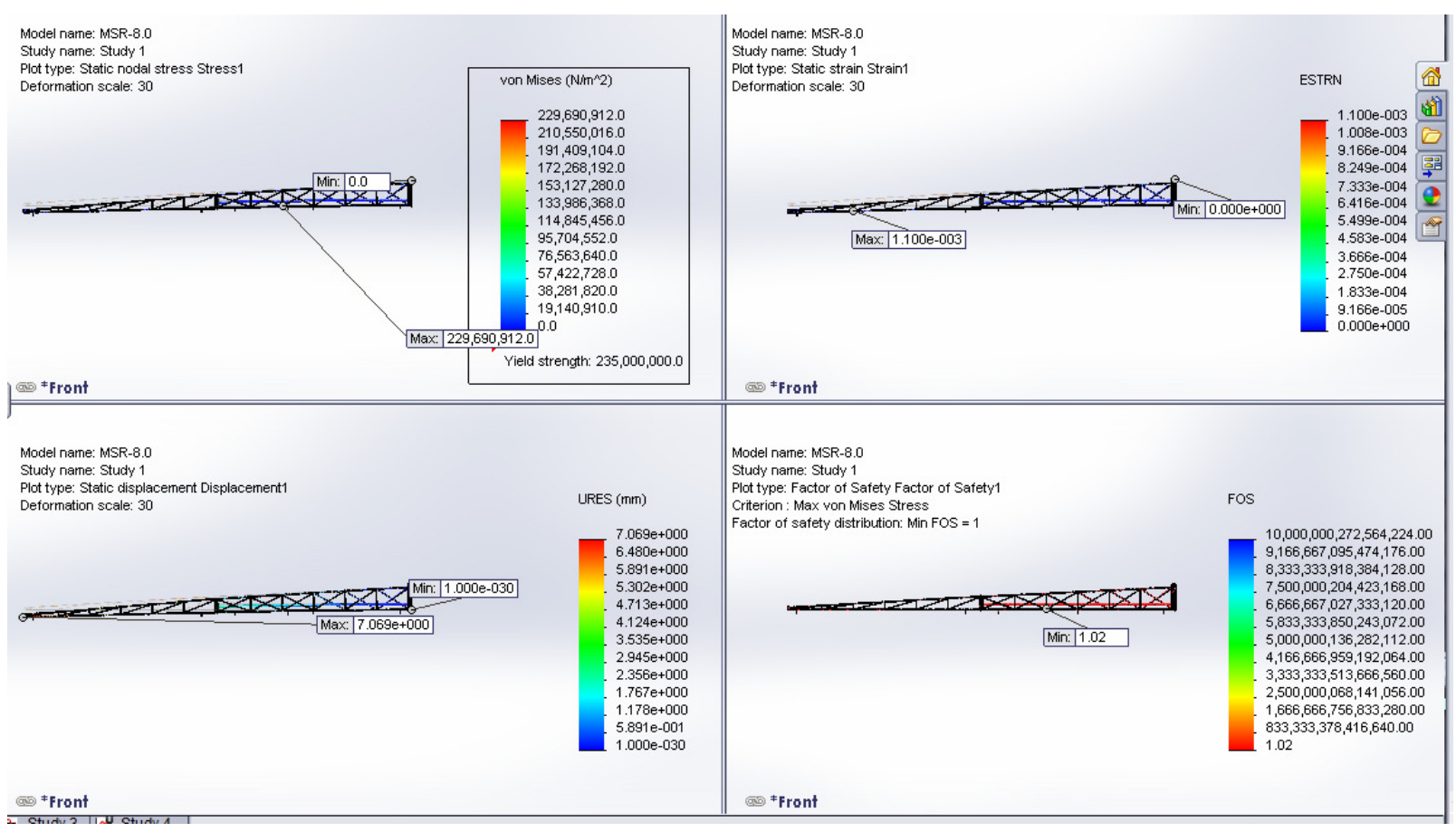

Fig. 5. Results of static linear analysis

The dynamic frequency response analysis performed in this study had as its main objective the determination of its own frequencies in all the constituent elements of the projected structure. The result of calculating frequencies or modal analysis is essentially in the list of a number of its own frequencies (in $\mathrm{Hz}$ ) (or pulses in $\mathrm{rad} \cdot \mathrm{s}^{-1}$ ), in the order starting from the lowest (fundamental frequency). There are also given the relative displacements on the directions and the resultant in the structure, for each vibration mode, separately. Also, colour maps of the field of relative displacements, 
component or resultant displacements were given. In Table 1 from the Solidworks program report, with which, using the Simulation module, frequency analysis was performed, a list of the first five frequencies corresponding to five vibration modes is presented.

Table 1

The first five frequencies corresponding to five vibration modes

\begin{tabular}{|c|c|c|}
\hline Vibration mode & Frequency, $\mathbf{H z}$ & ${\text { Pulses, } \mathbf{~ r a d} \cdot \mathbf{s}^{-1}}^{\mathbf{1}}$ \\
\hline 1 & 1.958 & 12.303 \\
\hline 2 & 4.2053 & 26.422 \\
\hline 3 & 6.2908 & 39.526 \\
\hline 4 & 13.364 & 83.968 \\
\hline 5 & 17.698 & 111.2 \\
\hline
\end{tabular}

As it is known, the main result of the modal analysis is the set of the calculated frequencies. In principle, it may be required to calculate a bigger number of its own frequencies. In fact, just the first few are useful. The most important is the fundamental frequency, which has the lowest value of the calculated ones. Most of the times, the list of the own frequencies is used to avoid resonant work regimes and, in general, resonance phenomena that may occur in various circumstances. In Fig. 6-10 the own frequencies and amplitude maps are given on the deformed shape of the structure in the vibration modes corresponding to each frequency.

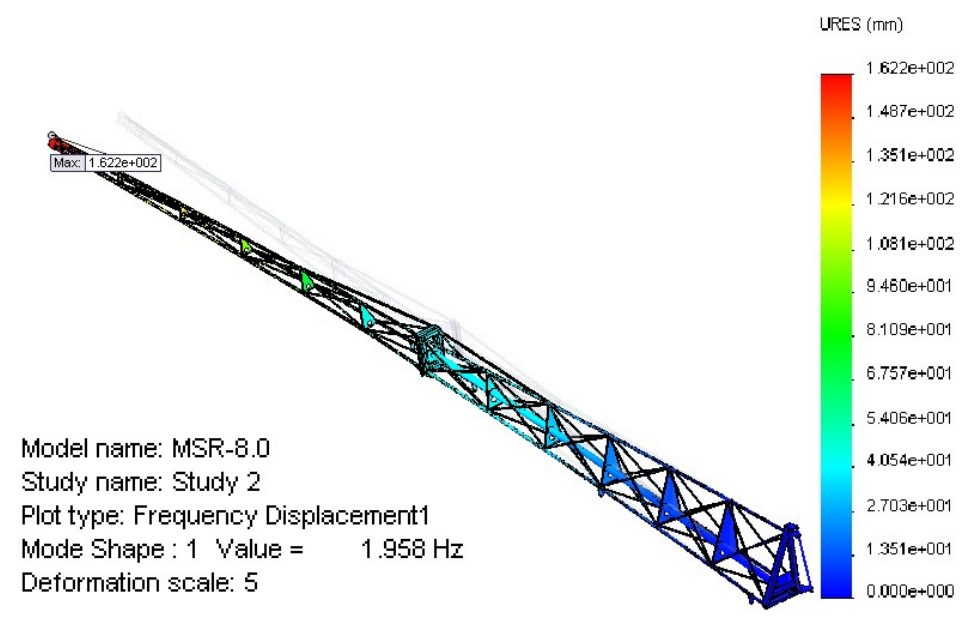

Fig. 6. Displacement map on the deformed shape of the boom for vibration mode $1,1.9580 \mathrm{~Hz}$

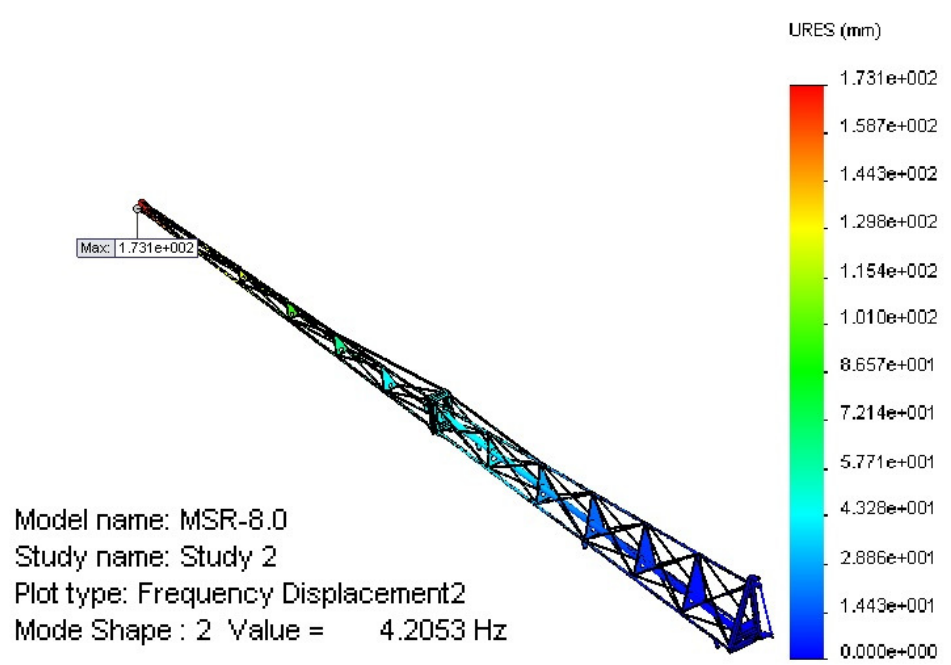

Fig. 7. Displacement map on the deformed shape of the boom for vibration mode $2,4.2053 \mathrm{~Hz}$ 


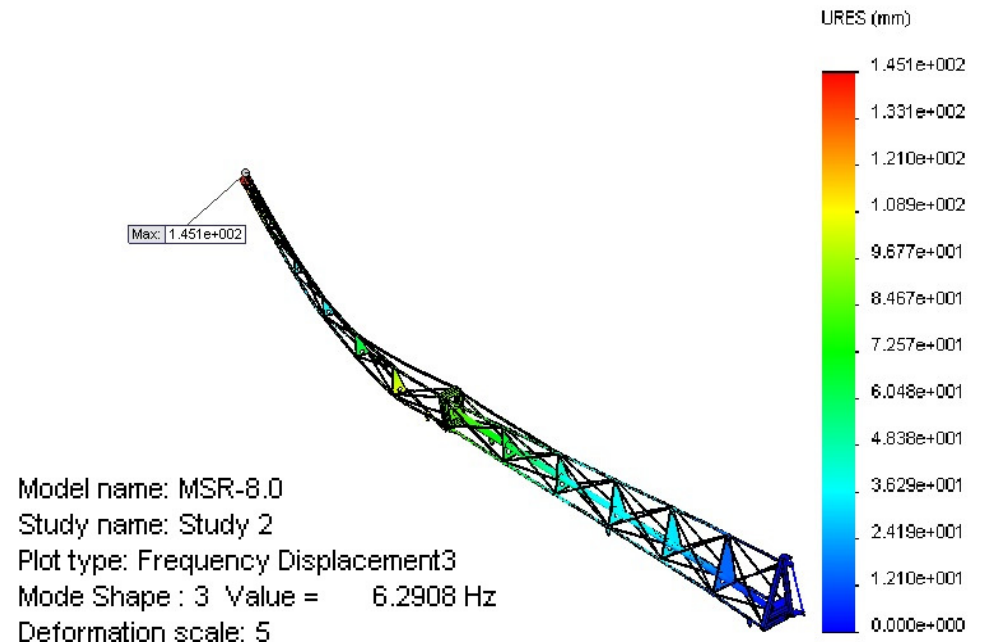

Fig. 8. Displacement map on the deformed shape of the boom for vibration mode $3,6.2908 \mathrm{~Hz}$

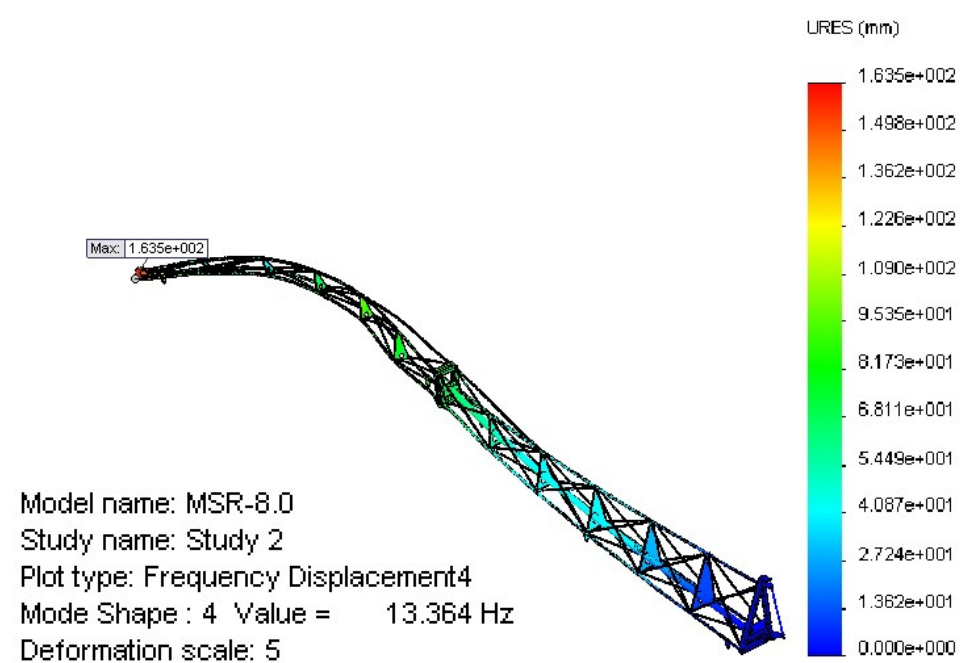

Fig. 9. Displacement map on the deformed shape of the boom for vibration mode $4,13.3640 \mathrm{~Hz}$

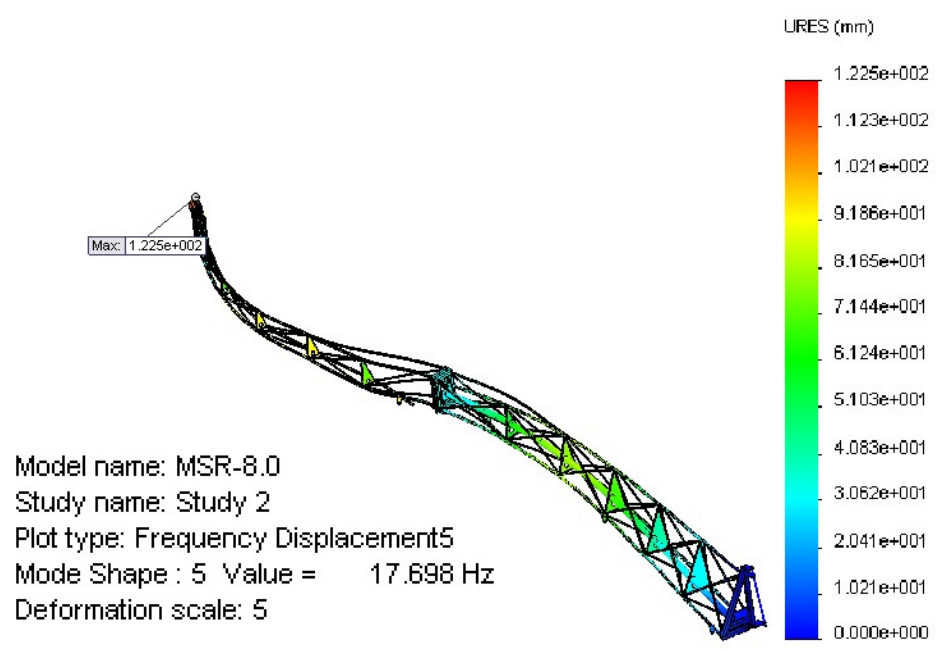

Fig. 10. Displacement map on the deformed shape of the boom for vibration mode $5,17.6980 \mathrm{~Hz}$

For the boom structure analyzed in this paper, we limited the number of frequencies calculated to 5. We considered that this way we cover all the basic frequencies that can occur in the working process of the spraying machine for different working speeds. The highest frequencies we have considered were those that originate, usually from the uneven field (Figure 11). 


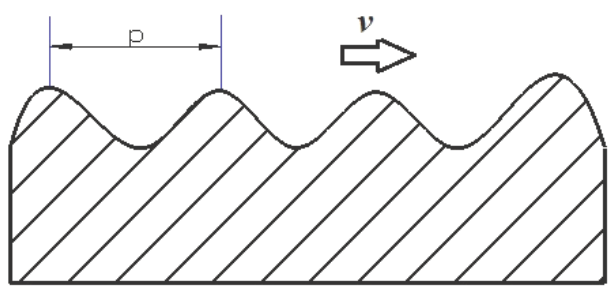

Fig. 11. Appearance of uneven terrain

Assuming that these bumps follow an approximately constant interval noted with $p$, we can calculate their frequency with the formula (1):

$$
f_{i}=\frac{v_{i}}{\bar{p}}, \mathrm{~s}^{-1}
$$

where $v_{i}$ - working speed of the tractor - sprayer aggregate, $\mathrm{m} \cdot \mathrm{s}^{-1}$;

$\bar{p}$ - average value of the distances between two successive field misalignments, $\mathrm{m}$.

(in this study, we considered $\bar{p}=0.3 \mathrm{~m}$, to simplify the calculus).

The diagram in Figure 12 shows the variation in the critical operating speed, depending on the resonance frequency for each vibration mode in Table 2. During working with the sprayer, the critical speed values shown in the diagram in Figure 12, or values close to them must be avoided. The reasons for avoiding the working speeds corresponding to the resonance frequencies are related to the serious damage to the boom and to unevenness of spraying on the ground.

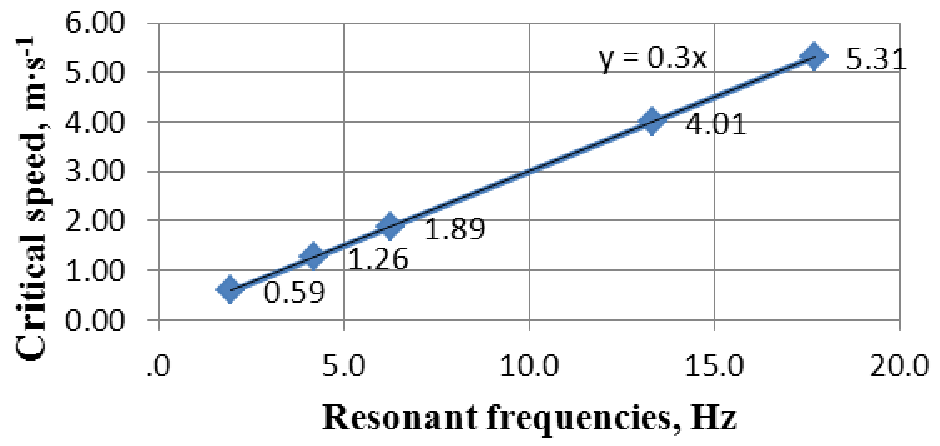

Fig. 12. Variation of critical speed, depending on resonance frequency

It is known from the practice and from the literature [2;3], that the working speed of a spraying machine is in the range of $1.6 \div 3.3 \mathrm{~m} \cdot \mathrm{s}^{-1}\left(6 \div 12 \mathrm{~km} \cdot \mathrm{h}^{-1}\right)$. According to the algorithm presented above, the resonance frequencies will be between $5.3 \mathrm{~Hz}$ and $11 \mathrm{~Hz}$. This range of resonant frequencies ranges between the vibration modes $2(4.2053 \mathrm{~Hz})$ and $4(13.364 \mathrm{~Hz})$, presented in Fig. 6-10, demonstrating the utility of the virtual simulation of the boom sprayer.

\section{Conclusions}

Following this structural study on the 24 m sprayer boom, several important conclusions can be drawn for further investigations. There was no risk of the structure material failure, because the value of von Misses maximum equivalent stress $\left(2.29 \cdot 10^{8} \mathrm{~N} \cdot \mathrm{m}^{-2}\right)$ was less than the yield strength $\left(2.35 \cdot 10^{8} \mathrm{~N} \cdot \mathrm{m}^{-2}\right)$. Also, the maximum relative displacement values $(7 \mathrm{~mm})$, corresponding to the boom end, guarantee that deviations from the working parameters dictated by agrotechnical requirements (e.g. working speed) are negligible. The value of the safety coefficient (1.02), in relation to its usual values in the practice of designing and manufacturing boom sprayers, shows that there is an important potential for optimizing this type of boom sprayers.

The analysis of the critical speed dependence on the resonance frequencies that can occur in the boom sprayer is particularly useful for designers and users of such machines. The critical speed values $\left(0.59 ; 1.26 ; 1.89 ; 4.01 ; 5.31 \mathrm{~m} \cdot \mathrm{s}^{-1}\right)$, or values close to them must be avoided. 
The usefulness of this analysis is particularly evident in the test phase and even in the first stages of operation, when the working regime of a boom sprayer should be improved.

\section{Acknowledgements}

This work was supported by a grant of the Romanian Ministery of Research and Innovation CCDI - UEFISCDI, project number PN-III-P1-1.2-PCCDI-2017-0254, 27PCCDI / 2018 and partially by PNIII-P2-2.1-BG-2016-0472, 33BG/2016, within PNCDI III.

\section{References}

[1] Anthonis J., Audenaert J., Ramon H. Design Optimisation for the Vertical Suspension of a Crop Sprayer Boom. Biosystems Engineering 90 (2), pp. 153-160

[2] Ramon H., De Baerdemaeker J. Spray boom motions and spray distribution-part 1: derivation of a mathematical relation. Journal of Agricultural Engineering Research, 66, 1997, pp. 23-29.

[3] Sinfort C., Lardoux Y., Miralles A., Enfalt P., Alness K., Andersson S. Comparison between measurements and predictions of spray pattern from a moving boom sprayer. Aspects of Applied Biology, 48, 1997, pp. 1-8.

[4] Buzdugan Gh., Fetcu L., Rades M.. Vibratii mecanice (Mechanical vibrations), Didactica and Pedagogica Publishing House, Bucharest, 1982.

[5] Cyril M. H., Charles E. C. Shock and Vibration, third edition, McGRAW - HILL BOOK COMPANY, 1961.

[6] Horea S., Dinamica structurilor (Dynamics of structures), Technical Publishing House, Bucharest, 1983.

[7] Mircea R., Vibratii mecanice (Mechanical vibrations), Printech Publishing House, 2008.

[8] Nuno M. M., Julio M. S.. Theoretical and Experimental Modal Analysis. Research Studies Press LTD., 1997.

[9] Cardei P., Matache M., Muraru V., Analiza structurala si material noi focalizate pe mecanica, mecatronica, mentenanta si exploatarea echipamentelor tehnice pentru agricultura si industrie alimentara (Structural analysis and new material focused on mechanics, mechatronics, maintenance and exploitation of technical equipment for agriculture and food industry). Terra Nostra Publishing House, Iasi, 2012.

[10]Lupea I., Tudose L., Stanescu C., Lupea M. Dynamic symulation and experiment on a sprayer boom structure. Annals of DAAAM for 2009 \& Proceedings of 20th DAAAM International Symposium, 2009.

[11] SolidWorks Simulation Hands-on Test Drive, Dassault Systèmes SolidWorks Corporation, Waltham, Massachusetts, USA. 